\title{
Systemic inflammation after critical illness: relationship with physical recovery and exploration of potential mechanisms
}

\author{
David M Griffith, ${ }^{1,2,3}$ Steff Lewis, ${ }^{4}$ Adriano G Rossi, ${ }^{2}$ Jillian Rennie, $^{2}$ Lisa Salisbury, ${ }^{5}$ \\ Judith L Merriweather, ${ }^{3}$ Kate Templeton, ${ }^{6}$ Timothy S Walsh, ${ }^{1,2,3}$ RECOVER Investigators ${ }^{1}$
}

\begin{abstract}
- Additional material is published online only. To view please visit the journal online (http://dx.doi.org/10.1136/ thoraxjnl-2015-208114).

${ }^{1}$ Department of Anaesthesia, Critical Care and Pain Medicine, University of Edinburgh, Edinburgh, UK

${ }^{2}$ MRC Centre for Inflammation Research, The Queen's Medical Research Institute, University of Edinburgh, Edinburgh, UK

${ }^{3}$ Department of Critical Care Royal Infirmary of Edinburgh, NHS Lothian, Edinburgh, UK

${ }^{4}$ Centre for Population Health Sciences, University of Edinburgh, Edinburgh, UK ${ }^{5}$ School of Health in Social Science, University of Edinburgh, Edinburgh, UK ${ }^{6}$ Department of Medical Microbiology, Royal Infirmary of Edinburgh, NHS Lothian, Edinburgh, UK
\end{abstract}

\section{Correspondence to} Dr David M Griffith, Department of Anaesthesia, Critical Care and Pain Medicine, University of Edinburgh, Royal Infirmary of Edinburgh, 57 Little France Crescent, Edinburgh EH16 4SA, UK;

david.m.griffith@ed.ac.uk

Received 23 November 2015 Revised 22 March 2016 Accepted 29 March 2016 Published Online First 26 April 2016

\section{SLinked}

- http://dx.doi.org/10.1136/ thoraxjnl-2016-208844

\section{CrossMark}

To cite: Griffith DM Lewis S, Rossi AG, et al. Thorax 2016;71:820-829.

\section{ABSTRACT}

Background Physical recovery following critical illness is slow, often incomplete and is resistant to rehabilitation interventions. We aimed to explore the contribution of persisting inflammation to recovery, and investigated the potential role of human cytomegalovirus (HCMV) infection in its pathogenesis.

Methods In an a priori nested inflammatory biomarker study in a post-intensive care unit (ICU) rehabilitation trial (RECOVER; ISRCTN09412438), surviving adult ICU patients ventilated $>48 \mathrm{~h}$ were enrolled at ICU discharge and blood sampled at ICU discharge $(n=184)$ and 3 month follow-up $(N=123)$. C-reactive protein $(C R P)$, human neutrophil elastase (HNE), interleukin (IL)-1 $\beta$, IL-6, IL-8, transforming growth factor $\beta 1$ (TGF $\beta 1$ ) and secretory leucocyte protease inhibitor (SLPI) were measured. HCMV IgG status was determined (previous exposure), and DNA PCR measured among seropositive patients (lytic infection). Physical outcome measures including the Rivermead Mobility Index (RMI) were measured at 3 months.

Results Many patients had persisting inflammation at 3 months (CRP >3 mg/L in 59\%; >10 mg/L in 28\%), with proinflammatory phenotype (elevated HNE, IL-6, IL-8, SLPI; low TGF $\beta 1$ ). Poorer mobility (RMI) was associated with higher $\operatorname{CRP}(\beta=0.13 ; p<0.01)$ and $\operatorname{HNE}(\beta=0.32 ; p=0.03)$, even after adjustment for severity of acute illness and preexisting co-morbidity (CRP $\beta=0.14 ; p<0.01$; HNE $\beta=0.30$; $p=0.04)$. Patients seropositive for HCMV at ICU discharge $(63 \%)$ had a more proinflammatory phenotype at 3 months than seronegative patients, despite undetectable HMCV by PCR testing.

Conclusions Inflammation is prevalent after critical illness and is associated with poor physical recovery during the first 3 months post-ICU discharge. Previous HCMV exposure is associated with a proinflammatory phenotype despite the absence of detectable systemic viraemia.

Trial registration number ISRCTN09412438, post results.

\section{INTRODUCTION}

Survivors of critical illness suffer physical weakness and functional impairment that can be severe and long-lasting. ${ }^{1}{ }^{2}$ Understanding of the pathophysiological processes that result in neuromuscular dysfunction during critical illness is improving, ${ }^{3}{ }^{4}$ but there is little evidence that interventions delivered after injury has occurred can improve physical outcomes. ${ }^{5}$ A systematic review of exercise-based rehabilitation trials initiated after intensive care
Key messages

What is the key question?

- Is systemic inflammation prevalent during recovery from critical illness and is it associated with physical recovery?

What is the bottom line?

- Systemic inflammation is highly prevalent during recovery from critical illness and is independently associated with physical recovery.

\section{Why read on?}

- We present inflammatory persistence as a plausible mechanism for poor physical function after critical illness and intriguing data that raise the possibility that human cytomegalovirus infection may contribute.

unit (ICU) discharge, ${ }^{6}$ and our recently published rehabilitation trial (RECOVER) ${ }^{7}$ suggest no effect on physical recovery when the intervention is started during the post-ICU period. Reasons for this lack of response are uncertain, but could include an established neuromuscular deficit or persisting pathophysiological processes blocking muscle recovery. The inflammatory nature of most critical illness raises the possibility that persisting inflammation could directly interfere with neuromuscular regeneration.

Damage to the neuromuscular unit occurs early during an episode of critical illness; identified risk factors include sepsis, inflammation, multiple organ failure and hyperglycaemia. ${ }^{8}$ Multiple studies have observed associations between inflammatory markers and muscle function in chronic inflammatory diseases, ${ }^{9-12}$ making it a plausible risk factor for poor physical recovery after critical illness. The prevalence of persisting inflammation and its association with recovery have not been described in unselected critical care cohorts. ${ }^{13}$

The factors that modulate persistence and resolution of inflammation after critical illness have also not been studied. A possible mechanism of persistence is viral reactivation, particularly of human cytomegalovirus (HCMV), which frequently reactivates during ICU admission in previously exposed 
individuals and is associated with poorer ICU outcomes and higher mortality. ${ }^{14-19}$ HCMV infection (both latent and lytic) can modify the innate immune response, ${ }^{20}{ }^{21}$ providing a biologically plausible mechanism for persisting inflammation.

In the RECOVER trial, we included, a priori, a nested study of inflammatory mediators in patients agreeing to regular blood sampling between enrolment (ICU discharge) and the primary outcome assessment (3 months postrandomisation). ${ }^{22}$ As the trial showed no effects on clinical outcomes, these data were suited to a cohort study design using both clinical and inflammatory mediator data as exposures, and the measures of physical function at 3-month follow-up as outcomes. We hypothesised that systemic inflammation is prevalent in ICU survivors following ICU discharge, and that the presence of persisting systemic inflammation is associated with poorer physical recovery. As an additional mechanistic analysis, we explored whether HCMV infection was associated with systemic inflammation and physical recovery.

\section{METHODS}

RECOVER was a randomised trial of increased hospital-based physical rehabilitation and information provision for ICU survivors. The protocol, description of the intervention and trial results have been published. ${ }^{722}{ }^{23}$ Participants were recruited from two ICUs in Edinburgh, Scotland from 1 December 2010, through 31 January 2013. Inclusion criteria were: receipt of $>48 \mathrm{~h}$ of continuous mechanical ventilation and deemed fit for ICU discharge. Exclusion criteria included a primary neurological diagnosis, receipt of palliative care, receipt of home ventilation, considered unable to provide informed consent, follow-up not feasible, discharge to a non-study hospital, aged $<18$ years and enrolment in another randomised controlled trial (RCT) with similar end points.

Both groups received existing ward-based physiotherapy, dietetics, occupational and speech/language therapy until hospital discharge. The intervention patients received enhanced hospitalbased physical rehabilitation and information provision that increased the frequency and intensity of multiple aspects of rehabilitation between enrolment and hospital discharge.

RECOVER was approved by the Scotland A Research Ethics Committee (10/MRE0018). Patients provided specific consent for inclusion in the blood sampling substudy during consent for the main study. The between-group comparison of outcomes in the trial found no clinically or statistically significant differences in measures of physical function, health-related quality of life (HRQoL), psychological morbidity or self-reported symptoms. ${ }^{7}$

\section{Sampling}

Blood was sampled at the time of randomisation (ICU discharge), and 3 months after ICU discharge by venepuncture or from an arterial line if present. Blood was stored at room temperature for $30 \mathrm{~min}$ and then centrifuged at $2500 \mathrm{~g}$ for $10 \mathrm{~min}$. Serum and plasma were stored at $-70^{\circ} \mathrm{C}$ prior to assay.

\section{Physical outcome}

Physical assessments included the Rivermead Mobility Index (RMI) (a validated measure of physical mobility ranging from 1 (unable to turn over in bed) to 15 (able to run)), ${ }^{24}$ handgrip strength (HGS; a measure of forearm muscle strength in $\mathrm{kg}$ )), ${ }^{25}$ the timed up and go test (TUG; a measure of lower limb strength and balance ${ }^{26}$ and the physical component of the Medical Outcomes Study Short Form 12 version 2 (PCS); a validated measure of HRQoL. ${ }^{27}$

\section{Biomarkers}

To detect ongoing inflammation we measured C-reactive protein (CRP) concentration. To further characterise inflammatory phenotype, we measured cytokines active during the initiation (interleukin $1 \beta$ (IL-1 $\beta$ ), IL-6), propagation (IL-8) and resolution (transforming growth factor $\beta 1$ (TGF $\beta 1$ ) and secretory leucocyte protease inhibitor (SLPI)) of inflammation. In addition, we measured human neutrophil elastase (HNE), a marker of ongoing neutrophil degranulation or non-apoptotic neutrophil death, to assess persisting neutrophil activation. The biomarkers measured were prespecified in an analysis plan submitted to the trial statistician (SL) prior to trial data being made available.

Inflammatory biomarkers were assayed by ELISA. All assays were carried out in duplicate. Coefficients of variation (CVs) were calculated for each duplicate pair. Where CVs were $>15 \%$ pipetting error was assumed, and assays were repeated.

\section{Human cytomegalovirus}

To establish prior exposure to HCMV, a quantitative indirect antiglobulin enzyme immunoassay (VIDAS CMV G, bioMérieux, Lyon, France) was used. HCMV IgG antibody was quantified in arbitrary units per millilitre $(\mathrm{aU} / \mathrm{mL})$. As per the manufacturers instructions, patients with serum concentration of $>6 \mathrm{aU} / \mathrm{mL}$ were considered to have positive serology (evidence of previous exposure). In patients with evidence of previous exposure, quantitative HCMV PCR was carried out to establish the presence of active lytic infection (detectable HCMV DNA). The lower detection limit of this assay was $160 \mathrm{IU} / \mathrm{mL}$.

\section{Analysis}

All analyses were carried out using IBM SPSS Statistics V.21. $\mathrm{p}<0.05$ was defined as statistically significant.

\section{Prevalence of systemic inflammation}

Inflammation prevalence was estimated with reference to CRP measurements in healthy adults. The percentage of surviving patients at each time point that had a serum CRP concentration of $>3$ and $10 \mathrm{mg} / \mathrm{L}$ representing the 90th and 99th centiles, respectively, was calculated. ${ }^{28}$

\section{Inflammatory profile}

For patients with complete paired data, biomarker concentration was reported at baseline and 3 months after ICU discharge. The median change in biomarker concentration between the two time points was calculated and assessed using Wilcoxon signed rank tests. To place data in a clinical context, upper reference limits for biomarkers were derived from published studies of healthy cohorts, and proportions of patients exceeding these limits calculated.

\section{Relationship with physical recovery}

The relationship between RMI and each of the inflammatory biomarkers was tested using univariable linear regression. This analysis was repeated for HGS, TUG and PCS.

To control for the effects of confounding, multivariable linear models were constructed to account for relevant pre-existing patient characteristics (age, gender and functional co-morbidity (as measured by the functional co-morbidity index $(\mathrm{FCI})$ ), and acute illness severity (APACHE 2 score and days of mechanical ventilation during ICU stay). The FCI is a validated 18-point measure capturing coexisting co-morbidity and concurrent disease, which is strongly associated with self-reported physical HRQoL. ${ }^{29}$ 
Due to violation of linear regression model assumptions (nonnormal distribution of predicted values of the outcome variable around the regression line) RMI, which was negatively skewed, required inverse natural $\log$ transformation (16- $\ln (\mathrm{RMI})$ ) prior to regression analysis. Inflammatory biomarkers, ventilator days and TUG were positively skewed and required natural log transformation prior to regression analysis. For zero value biomarker concentrations, 0.001 was added to allow transformation.

Role of cytomegalovirus in post-ICU inflammation and recovery The percentage of patients with prior exposure to HCMV (HCMV IgG positive) and the proportion of these with lytic infection (detectable HCMV PCR) were reported at ICU discharge and at 3 months. The concentration of each inflammatory biomarker was compared between patients previously exposed to HCMV and those not previously exposed. To explore the potential for HCMV to affect physical function, physical outcomes were compared between these groups using an independent samples median test. In addition, to test whether HCMV seropositivity confounds the association between inflammation (as measured by CRP and RMI) tested in the previous section, we added HCMV seropositivity as an additional variable in the multivariable linear regression model. Our analysis plan aimed to assess the relationship between ongoing lytic infection and measures of recovery, but the low number of patients with lytic infection meant meaningful comparisons could not made.

\section{Missing data}

The primary analysis was a complete case analysis. To ensure that the results of this analysis were not subject to bias introduced by assuming the missing patients were similar to those included, a sensitivity analysis was carried out imputing data according to two different assumptions (see online supplementary data). 3031

\section{RESULTS}

\section{Patients}

Two hundred and forty patients were recruited to the RECOVER study; of these, 193 (80\%) consented to blood sampling (figure 1). Baseline characteristics of the included patients are shown in table 1 .

\section{Physical outcomes}

The 3-month outcome data showing central tendency and dispersion are presented in table 2 .

\section{Prevalence of systemic inflammation}

At ICU discharge, $141 / 184$ (77\% (95\% CI $70 \%$ to $82 \%)$ ) of patients had a CRP concentration of $>10 \mathrm{mg} / \mathrm{L}$ and $173 / 184$ (94\% (95\% CI $90 \%$ to $97 \%)$ ) had a CRP concentration of $>3 \mathrm{mg} / \mathrm{L}$. Three months after ICU discharge, 34/123 (28\% (95\% CI 21\% to 36\%)) of patients had a CRP concentration of $>10 \mathrm{mg} / \mathrm{L}$ and $72 / 123$ (59\% (95\% CI 50\% to 67\%)) of patients had a CRP concentration $>3 \mathrm{mg} / \mathrm{L}$. For complete cases $(\mathrm{n}=118)$ CRP concentration fell from $27.9 \mathrm{mg} / \mathrm{L}(10.4-63.1)$ at baseline to $4.4 \mathrm{mg} / \mathrm{L}(1.2-12.0)$ at 3 months with a median change of $-20.7 \mathrm{mg} / \mathrm{L}(95 \% \mathrm{CI}-26.9$ to $-14.5 ; \mathrm{p}<0.01)$. For this same complete case cohort $(n=118)$, figure 2 describes the inflammatory outcome of patients with CRP concentrations that had high (>10 mg/L), medium (3-10 mg/L) and low ( $<3 \mathrm{mg} / \mathrm{L})$ CRP concentration at ICU discharge.

\section{Inflammatory profile}

At ICU discharge, HNE, IL-6, IL-8 and SLPI were elevated compared with previously studied healthy populations (table 3 ).

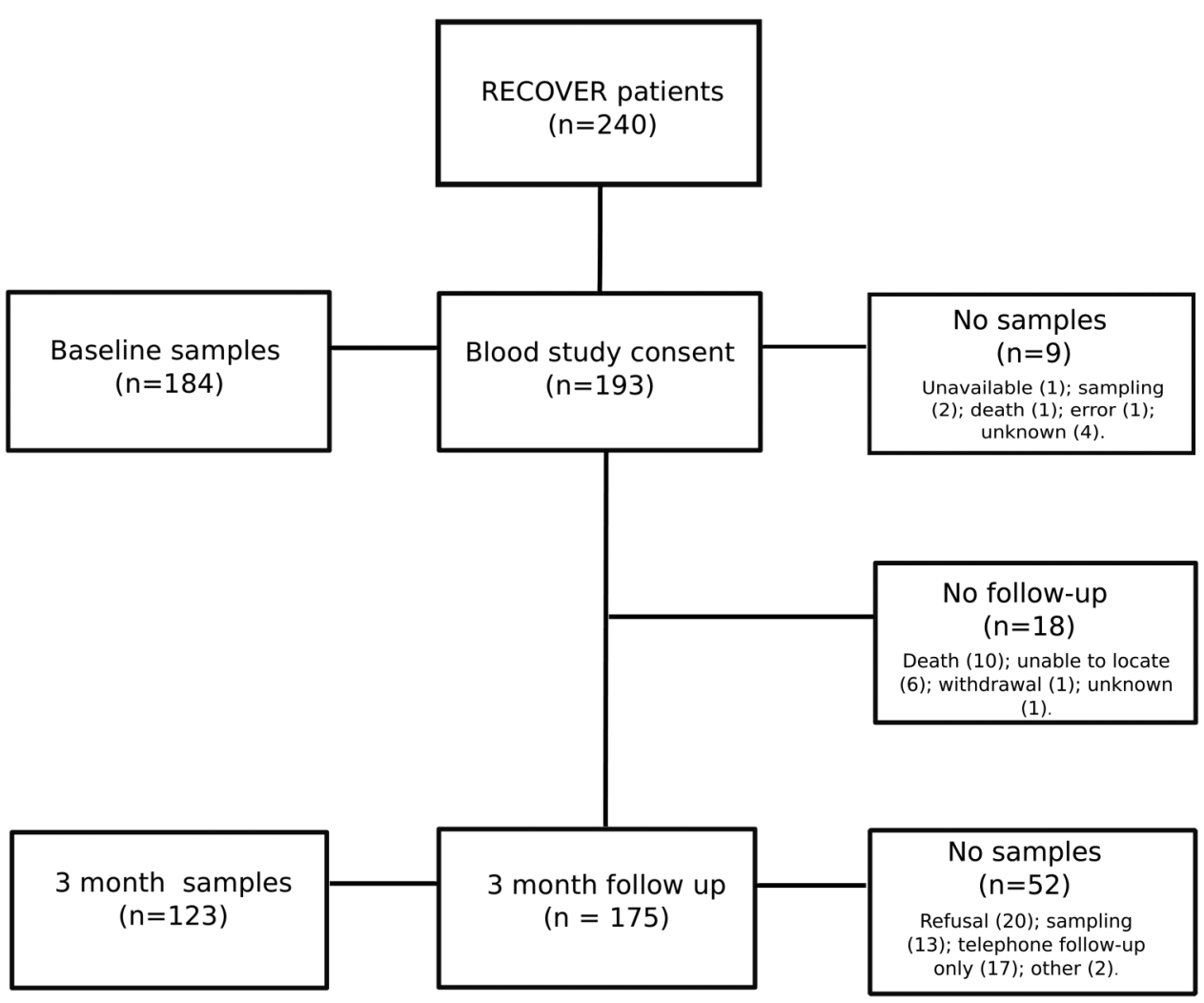

Figure 1 Study flow diagram. 
Table 1 Patient characteristics presented for all consenting patients $(n=193)$, and for patients grouped according to CRP tertile at 3 months after ICU discharge $(n=123)$

\begin{tabular}{|c|c|c|c|c|}
\hline & All $(n=193)$ & $\begin{array}{l}\text { Lower tertile of CRP } \\
(<2.1 \mathrm{mg} / \mathrm{L})(\mathrm{n}=41)\end{array}$ & $\begin{array}{l}\text { Middle tertile of CRP } \\
(2.1-7.9 \mathrm{mg} / \mathrm{L})(\mathrm{n}=41)\end{array}$ & $\begin{array}{l}\text { Upper tertile of CRP } \\
\text { (>7.9 mg/L) }(n=41)\end{array}$ \\
\hline Age (mean (SD)) & $61(14)$ & $59(13)$ & $62(11)$ & $58(15)$ \\
\hline Male (n (\%)) & $117(61)$ & $24(59)$ & $27(66)$ & $24(59)$ \\
\hline Functional co-morbidity index (mean (SD)) & $3(2)$ & $3(2)$ & $3(2)$ & $3(2)$ \\
\hline APACHE 2 (mean (SD)) & $21(7)$ & $22(7)$ & $19(8)$ & $21(6)$ \\
\hline Days of mechanical ventilation (median (Q1, Q3)) & $8(5,14)$ & $8(4,16)$ & $9(5,14)$ & $9(6,15)$ \\
\hline ICU length of stay (median (Q1, Q3)) & $11(7,18)$ & $10(7,18)$ & $11(7,18)$ & $12(8,19)$ \\
\hline Vasopressors (n (\%)) & $141(73)$ & $28(83)$ & $31(76)$ & $31(78)$ \\
\hline Renal replacement therapy (n (\%)) & $52(27)$ & $10(24)$ & $10(24)$ & $12(30)$ \\
\hline \multicolumn{5}{|l|}{ Diagnosis category (n (\%)) } \\
\hline Respiratory & $69(34)$ & $17(41)$ & $14(34)$ & $15(37)$ \\
\hline Cardiovascular & $53(27)$ & $12(29)$ & $15(37)$ & $8(20)$ \\
\hline Neurological & $6(3)$ & $1(2)$ & $1(2)$ & $1(2)$ \\
\hline Renal & $3(2)$ & $1(2)$ & $0(0)$ & $0(0)$ \\
\hline Gastrointestinal & $52(27)$ & $6(15)$ & $9(22)$ & $16(39)$ \\
\hline Trauma & $5(3)$ & $1(2)$ & $2(5)$ & $1(2)$ \\
\hline Miscellaneous & $5(3)$ & $3(7)$ & $0(0)$ & $0(0)$ \\
\hline
\end{tabular}

CRP, C-reactive protein; ICU, intensive care unit.

TGFß1 concentration was reduced. Median concentrations of proinflammatory biomarkers (HNE, IL-6 and IL-8) decreased significantly over the 3-month time horizon (with the exception of IL-1 $\beta$ which was low at both time points). Many patients still demonstrated elevated concentrations compared with the comparative healthy population values. For the proresolution biomarkers, TGF $\beta 1$ concentration further decreased at 3 months compared with baseline with values at both time points lower than healthy values. Most patients had suppressed levels of TGF $\beta 1$ at both time points. SLPI concentrations decreased over the 3-month period, with most patients having higher values than comparator populations at both time points. Overall, the 3-month pattern at population level was of ongoing inflammation (elevated CRP, HNE and IL8) with evidence of reduced proresolution signalling (reduced/suppressed TFG $\beta 1$ ).

\section{Relationship with physical recovery}

In the univariable analysis, HNE and CRP were significantly associated with RMI 3 months after ICU discharge (table 4), with higher concentrations of these biomarkers being associated with poorer mobility. This association persisted when tested in multivariable linear regression models to adjust for potential confounding factors (age, gender, FCI, APACHE 2 score and days of mechanical ventilation), suggesting HNE and CRP were independently associated with RMI 3 months after ICU discharge.

IL-8 was significantly associated with HGS at 3 months on univariate testing. After adjustment for confounding, higher

Table 2 Physical outcome at 3 months

\begin{tabular}{lll}
\hline Measure & $\mathbf{n}$ & \\
\hline Rivermead mobility index (median (Q1, Q3)) & 175 & $14.0(12,15)$ \\
Hand grip strength (kg) (mean (SD)) & 153 & $21.9(8.8)$ \\
Timed up and go (seconds) (median (Q1, Q3)) & 147 & $10.2(7.7,13.3)$ \\
Physical component score of SF12v2 (mean (SD)) & 161 & $35.1(11.4)$ \\
\hline
\end{tabular}

concentrations of CRP, IL-8 and SLPI were significantly associated with lower HGS.

There was no significant association observed between inflammatory markers and TUG, or the PCS.

To add clinical context to this relationship we compared HNE and CRP concentration in patients with good mobility (upper three quartiles of RMI (RMI $\geq 11 ; n=144)$ ) and poor mobility (lower quartile of RMI (RMI $<11$; n=31)) at the same time point. Patients with poor mobility had greater CRP concentration (median $11.1 \mathrm{mg} / \mathrm{L}$ (IQR 4.1-21.8) versus $3.7 \mathrm{mg} / \mathrm{L}$ (IQR 0.9-9.7); median difference $7.3 \mathrm{mg} / \mathrm{L}(95 \% \mathrm{CI}$ 2.0 to $10.8 ; \mathrm{p}<0.01)$ ) and HNE concentration (median $117.0 \mathrm{ng} / \mathrm{mL}$ (IQR 102.6-172.1) versus $103.2 \mathrm{ng} / \mathrm{mL}$ (IQR 85.7-135.8); median difference $13.8 \mathrm{ng} / \mathrm{mL}$ (95\% CI -1.0 to 42.0; $\mathrm{p}=0.06)$ ) when compared with patients with good mobility (figure 3).

Inflammatory biomarkers at ICU discharge were significantly correlated with biomarkers at 3 months (table 5). To test whether inflammation at ICU discharge was an important confounder of the relationship between persistent inflammation (CRP at 3 months) and recovery (RMI at 3 months), we added $\mathrm{CRP}$ at ICU discharge to our earlier linear regression model (table 6). We found no association between CRP at ICU discharge and RMI at 3 months, and adding it as a covariate to the model did not alter the relationship between CRP and RMI when both were measured at 3 months.

\section{Role of cytomegalovirus in post-ICU inflammation}

At ICU discharge, 115/183 (63\%) of patients were HCMV IgG positive indicating previous exposure to HCMV (one patient had insufficient sample to perform $\operatorname{IgG}$ analysis). Of the IgG-positive patients, $13 / 114$ of patients (11\%) had evidence of lytic infection (detectable HCMV DNA on plasma PCR assay) (one patient had insufficient sample to perform the DNA PCR). At 3-month follow-up, no patients had evidence of ongoing lytic infection.

At ICU discharge, patients previously exposed to HCMV had similar CRP concentrations, but greater concentrations of HNE and a lower concentration of the proresolution mediator TGF $\beta 1$ 
Figure 2 Inflammatory fate of patients with low $(<3 \mathrm{mg} / \mathrm{L})$, medium (3-10 mg/L) and high (>10 mg/L) C-reactive protein (CRP) concentration. For the 118 patients with complete data at both time points, patients were categorised at intensive care unit (ICU) discharge, then again at 3 months.

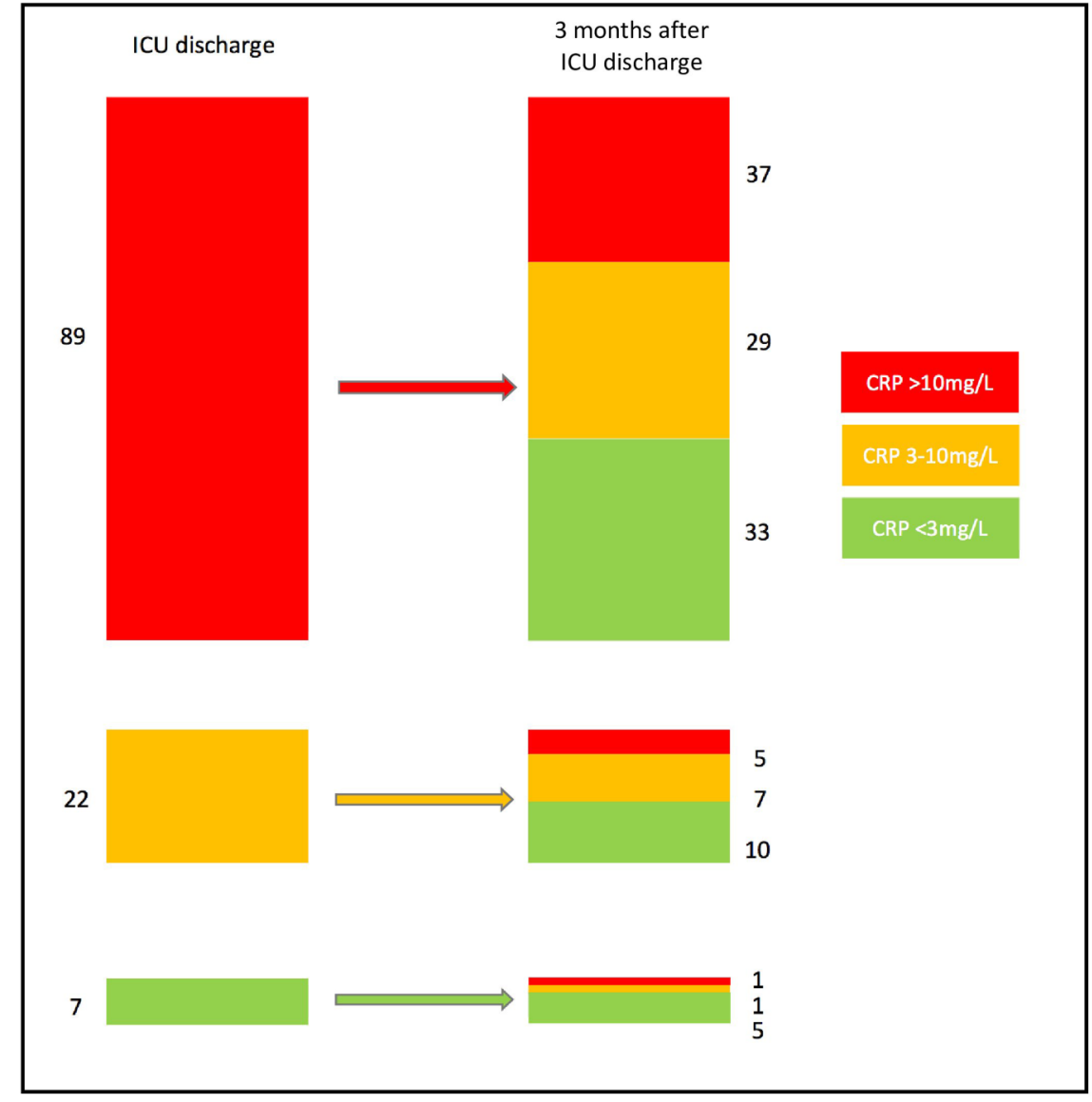

suggesting a more proinflammatory phenotype associated with previous HCMV exposure (table 7). At 3 months, despite an overall fall in inflammatory biomarkers, patients previously exposed to HCMV still had significantly greater circulating HNE and lower circulating TGF $\beta 1$. Very small differences in physical outcomes were noted according to previous HCMV exposure, although this reached statistical significance for the TUG test, which was slower in HCMV-positive patients (table 8).

As HCMV exposure increases with age, ${ }^{37}$ we assessed the potential confounding role of age (and other baseline variables) in the association between HCMV and physical recovery. Baseline characteristics according to HCMV IgG status are shown in table 9. None of the baseline variables (including age) differed significantly according to HCMV exposure group.
We assessed whether HCMV seropositivity may be a confounder in the relationship between inflammation (measured by CRP) and RMI. We found no independent relationship between HCMV seropositivity and RMI at 3 months. The addition of HCMV seropositivity as a covariate also had no influence on the strength of the relationship between $\ln (\mathrm{CRP})$ and $\ln$ (16-RMI), which remained highly significant ( $\beta 0.15$ (95\% CI 0.06 to 0.24$) \mathrm{p}<0.01)$. These sensitivity analyses are presented in the online supplementary data.

\section{DISCUSSION}

In a preplanned secondary analysis of patients enrolled in a randomised controlled trial of a rehabilitation intervention, we demonstrated a high prevalence of systemic inflammation in

Table 3 Inflammatory biomarker concentration at baseline and 3 months in patients who survived and had blood sampling at both time points

\begin{tabular}{|c|c|c|c|c|c|c|c|c|}
\hline \multirow[b]{2}{*}{ Biomarker } & \multirow[b]{2}{*}{$\mathrm{N}$} & \multirow{2}{*}{$\begin{array}{l}\text { Healthy from } \\
\text { previous studies } \\
\text { Mean (SD) }\end{array}$} & \multicolumn{2}{|l|}{ Baseline } & \multicolumn{2}{|l|}{3 months } & \multicolumn{2}{|c|}{ Change from baseline to 3 months } \\
\hline & & & Median (IQR) & $\begin{array}{l}\text { Proportion } \\
\text { elevated (\%) }\end{array}$ & Median (IQR) & $\begin{array}{l}\text { Proportion } \\
\text { elevated (\%) }\end{array}$ & $\begin{array}{l}\text { Hodges-Lehmann median } \\
\text { difference }(95 \% \mathrm{Cl})\end{array}$ & p Value \\
\hline HNE $(n g / m L)$ & 112 & $77.1(35.5)^{32}$ & $145.2(112.8-199.5)$ & 48 & $110.3(88.3-142.5)$ & 23 & $-36.9(-49.3$ to -23.6$)$ & $<0.01$ \\
\hline $\mathrm{IL}-1 \beta(\mathrm{pg} / \mathrm{mL})$ & 111 & $0.8(0.1)^{33}$ & $0.0(0.0-15.0)$ & 39 & $0.0(0.0-7.6)$ & 30 & $0.0(0.0$ to 0.0$)$ & 0.73 \\
\hline IL-6 (pg/mL) & 111 & $9(12)^{33}$ & $25.2(8.0-85.5)$ & 45 & $6.7(0.0-37.2)$ & 26 & $-16.5(-28.4$ to -8.1$)$ & $<0.01$ \\
\hline IL-8 (pg/mL) & 111 & $3.2(2.5)^{34}$ & $27.3(12.2-63.0)$ & 85 & $8.6(1.2-33.3)$ & 51 & $-14.4(-20.0$ to -9.8$)$ & $<0.01$ \\
\hline TGF $\beta 1$ (ng/mL) & 116 & $36.4(8.23)^{35}$ & $12.1(8.5-16.04)$ & $0(91)^{*}$ & $10.1(7.8-12.5)$ & $0(97)^{*}$ & $-2.0(-2.9$ to -1.2$)$ & $<0.01$ \\
\hline SLPI (ng/mL) & 118 & $36.4(2.3)^{36}$ & $59.3(44.7-79.0)$ & 78 & $47.4(37.3-60.8)$ & 64 & $-10.4(-15.6$ to -5.4$)$ & $<0.01$ \\
\hline
\end{tabular}

Median difference and $p$ values have been calculated to reflect change over 3 months. To add context, mean (SD) concentrations in previous studied healthy populations are quoted and the proportion in our cohort with elevated biomarker concentration (>2 SD above mean in previously studied healthy cohort) are calculated.

*Starred values represent proportion with abnormally low TGF $\beta 1$ concentration (>2SD below mean in previously studied healthy cohort).

HNE, human neutrophil elastase; SLPI, secretory leucocyte protease inhibitor; TGF $\beta 1$, transforming growth factor $\beta 1$; IL, interleukin. 
Table 4 Linear regression of individual biomarkers with physical outcome measures at 3 months after ICU discharge

\begin{tabular}{|c|c|c|c|c|c|c|c|c|c|}
\hline \multirow[b]{3}{*}{ Outcome } & \multirow[b]{3}{*}{ Biomarker } & \multicolumn{4}{|c|}{ Unadjusted } & \multicolumn{4}{|c|}{ Adjusted } \\
\hline & & \multirow[b]{2}{*}{$\boldsymbol{\beta}$} & \multicolumn{2}{|l|}{$95 \% \mathrm{Cl}$} & \multirow[b]{2}{*}{ p Value } & \multirow[b]{2}{*}{$\boldsymbol{\beta}$} & \multicolumn{2}{|l|}{$95 \% \mathrm{Cl}$} & \multirow[b]{2}{*}{ p Value } \\
\hline & & & Lower & Upper & & & Lower & Upper & \\
\hline \multirow[t]{7}{*}{ RMI } & CRP & 0.13 & 0.05 & 0.22 & $<0.01$ & 0.14 & 0.06 & 0.23 & $<0.01$ \\
\hline & HNE & 0.32 & 0.03 & 0.60 & 0.03 & 0.30 & 0.02 & 0.59 & 0.04 \\
\hline & IL-1 $\beta$ & -0.01 & -0.04 & 0.01 & 0.32 & -0.01 & -0.04 & 0.02 & 0.52 \\
\hline & IL-6 & 0.00 & -0.02 & 0.03 & 0.80 & 0.01 & -0.02 & 0.04 & 0.59 \\
\hline & IL-8 & 0.03 & -0.01 & 0.06 & 0.13 & 0.03 & 0.00 & 0.07 & 0.06 \\
\hline & TGF $\beta 1$ & 0.05 & -0.34 & 0.43 & 0.80 & 0.07 & -0.31 & 0.45 & 0.73 \\
\hline & SLPI & 0.15 & -0.11 & 0.41 & 0.26 & 0.14 & -0.13 & 0.40 & 0.31 \\
\hline \multirow[t]{7}{*}{ TUG } & CRP & 0.64 & -0.02 & 0.10 & 0.15 & 0.05 & 0.01 & 0.11 & 0.10 \\
\hline & HNE & 0.15 & -0.04 & 0.33 & 0.13 & 0.14 & -0.05 & 0.32 & 0.15 \\
\hline & IL-1 $\beta$ & 0.00 & -0.02 & 0.62 & 0.82 & 0.01 & -0.01 & 0.02 & 0.58 \\
\hline & IL-6 & 0.00 & -0.02 & 0.02 & 0.85 & 0.01 & -0.01 & 0.02 & 0.50 \\
\hline & IL-8 & 0.01 & -0.01 & 0.03 & 0.38 & 0.02 & 0.00 & 0.04 & 0.12 \\
\hline & TGF $\beta 1$ & -0.17 & -0.42 & 0.07 & 0.16 & -0.16 & -0.39 & 0.08 & 0.19 \\
\hline & SLPI & 0.08 & -0.09 & 0.25 & 0.34 & 0.05 & -0.12 & 0.21 & 0.58 \\
\hline \multirow[t]{7}{*}{ HGS } & CRP & -0.51 & -1.57 & 0.55 & 0.35 & -0.95 & -1.85 & -0.06 & 0.04 \\
\hline & HNE & -3.20 & -6.58 & 0.18 & 0.06 & -2.60 & -5.43 & -0.22 & 0.07 \\
\hline & IL-1 $\beta$ & 0.03 & -0.29 & 0.35 & 0.87 & 0.01 & -0.27 & 0.28 & 0.97 \\
\hline & IL-6 & -0.05 & 0.38 & 0.28 & 0.76 & -0.12 & -0.40 & 0.15 & 0.38 \\
\hline & IL-8 & -0.51 & -0.90 & -0.13 & 0.01 & -0.41 & -0.75 & -0.08 & 0.02 \\
\hline & TGF $\beta 1$ & -1.37 & -5.81 & 3.08 & 0.54 & -1.76 & -5.55 & 2.04 & 0.36 \\
\hline & SLPI & -2.90 & -5.90 & 0.09 & 0.06 & -2.72 & -5.33 & -0.11 & 0.04 \\
\hline \multirow[t]{7}{*}{ PCS } & CRP & 0.24 & -1.12 & 1.60 & 0.72 & 0.27 & -1.08 & 1.62 & 0.69 \\
\hline & HNE & -0.62 & -5.08 & 3.85 & 0.79 & -0.64 & -5.09 & 3.82 & 0.78 \\
\hline & IL-1 $\beta$ & 0.08 & -0.33 & 0.49 & 0.71 & -0.01 & -0.43 & 0.40 & 0.95 \\
\hline & IL-6 & 0.14 & -0.28 & 0.56 & 0.51 & 0.09 & -0.33 & 0.51 & 0.66 \\
\hline & IL-8 & -0.20 & -0.72 & 0.31 & 0.43 & -0.40 & -0.92 & 0.12 & 0.13 \\
\hline & TGF $\beta 1$ & 0.21 & -0.55 & 5.96 & 0.94 & -0.01 & -5.69 & 5.72 & 1.00 \\
\hline & SLPI & -1.68 & -5.58 & 2.22 & 0.40 & -1.61 & -5.58 & 2.36 & 0.42 \\
\hline
\end{tabular}

ICU survivors at ICU discharge and 3 months follow-up. We observed a significant relationship between inflammation and physical recovery that persisted after adjusting for measures of pre-existing co-morbidity and acute illness severity. Patients had evidence of persisting proinflammatory and impaired proresolution signalling during the study period. In an exploratory analysis, we found a more pronounced proinflammatory phenotype in patients previously exposed to HCMV both at ICU discharge and 3 months follow-up. This supports the hypothesis that this might mediate, in part, the association between persisting inflammation and functional recovery.

Our study had a number of strengths. First, the rates of enrolment and follow-up were high, reducing the risk of attrition bias. We also undertook sensitivity analyses in which missing data were imputed to allow us to ensure potential bias from missing data was assessed. Second, we adjusted for likely confounders. The most important was the use of the FCI to adjust for pre-illness physical function (an important determinant of physical recovery after acute illness ${ }^{38}$ ). The FCI is a measure of important co-morbidities, which correlates strongly with physical quality of life scores. ${ }^{39}$ This may not have completely controlled for pre-illness physical function, but is more objective and valid than patient recall of physical abilities. Most previous studies of post-ICU recovery have made no adjustment for preillness health status. We did not adjust for case mix in our analysis primarily because the study was not powered to allow it, but reassuringly observed very little variation in case mix across CRP tertiles. Finally, the measured biomarkers were predefined to reflect initiation, propagation and resolution of the acute inflammatory response to provide a balanced picture of the inflammatory profile.

Our study had limitations. First, our assertion that inflammatory markers were elevated in ICU survivors was based on comparison with previously published data in other populations; these were limited by performance of the assays and the populations studied. Second, our analysis relied on the physical function metrics used in RECOVER, limiting the discriminant ability for studying the pathophysiological processes affecting muscle recovery. Third, our patients were ventilated for $>48 \mathrm{~h}$ so our findings may not be generalisable to all ICU cohorts. Fourth, we did not adjust our formal analysis for multiple comparisons as it was considered explorative and hypothesis-generating. This may have led to type 1 error. Despite this, for our main end point (adjusted association between CRP and RMI), the $\mathrm{p}$ value of 0.001 would remain significant when measured against a Bonferroni-adjusted $\mathrm{p}$ value threshold of 0.002 . Finally, we could not definitely attribute causality between inflammation and physical recovery because we were unable to establish temporality due to the complex nature of the inflammatory response and the trial design.

Inflammatory persistence in ICU survivors is of potential clinical relevance. We have shown that it is highly prevalent, affecting 50\%-67\% of survivors 3 months following ICU discharge. This finding is in keeping with a previous study in 24 anaemic ICU survivors who showed elevation of CRP up to 13 weeks after ICU discharge. ${ }^{40}$ The aetiology of this inflammatory signal 

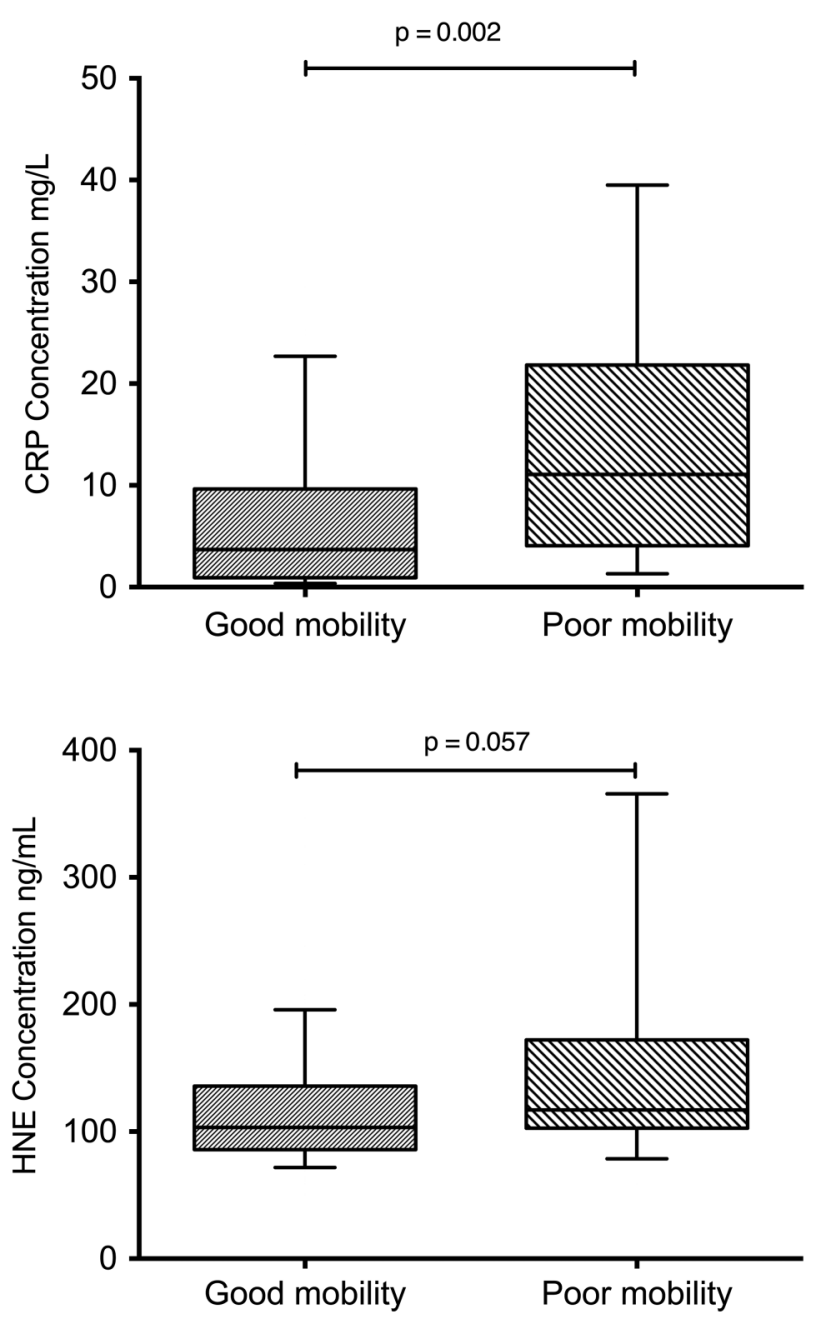

Figure 3 Box and whisker plots showing C-reactive protein (CRP) and human neutrophil elastase (HNE) concentration in patients with good mobility and poor mobility. Whiskers represent 10 th and 90 th centiles.

is unclear. Persistence of the acute inflammatory response is one mechanism, but other potential explanations such as pre-existing inflammation (with return to baseline), intercurrent infection (eg, subclinical) or an undiagnosed focus of inflammation (eg, within lung or muscle) are also plausible. A high proportion of patients $(28 \%)$ were readmitted to hospital between ICU discharge and 3 months follow-up in the RECOVER trial. Detailed data concerning the reasons for readmission are not available,

Table 5 Linear relationship between natural log transformed inflammatory biomarkers at baseline (ICU discharge) and follow-up

\begin{tabular}{llllrl}
\hline & & & \multicolumn{2}{l}{$95 \% \mathrm{Cl}$} & \\
\cline { 5 - 6 } Biomarker & $\mathbf{N}$ & $\mathbf{B}$ & Lower & Upper & p Value \\
\hline CRP & 118 & 0.37 & 0.14 & 0.61 & $<0.01$ \\
HNE & 112 & 0.23 & 0.08 & 0.38 & $<0.01$ \\
IL-1 $\beta$ & 111 & 0.76 & 0.65 & 0.89 & $<0.01$ \\
IL-6 & 111 & 0.74 & 0.54 & 0.93 & $<0.01$ \\
IL-8 & 111 & 1.03 & 0.78 & 11.29 & $<0.01$ \\
TGF $\beta 1$ & 116 & 0.33 & 0.20 & 0.45 & $<0.01$ \\
SLPI & 118 & 0.68 & 0.52 & 0.83 & $<0.01$ \\
\hline
\end{tabular}

CRP, C-reactive protein; HNE, human neutrophil elastase; ICU, intensive care unit; SLPI, secretory leucocyte protease inhibitor; TGF $\beta 1$, transforming growth factor $\beta 1$; IL, interleukin.
Table 6 Sensitivity analysis showing effect of adjusting for CRP at baseline

\begin{tabular}{|c|c|c|c|c|c|}
\hline & \multirow[b]{2}{*}{ Covariates } & \multirow[b]{2}{*}{ B } & \multicolumn{2}{|l|}{$95 \% \mathrm{Cl}$} & \multirow[b]{2}{*}{ p Value } \\
\hline & & & Lower & Upper & \\
\hline \multirow[t]{6}{*}{ Original analysis } & Ventilator days* & 0.05 & -0.13 & 0.23 & 0.58 \\
\hline & Age & 0.00 & -0.01 & 0.01 & 0.71 \\
\hline & Gender & 0.11 & -0.16 & 0.37 & 0.43 \\
\hline & APACHE 2 & 0.01 & -0.01 & 0.03 & 0.49 \\
\hline & $\mathrm{FCl}$ & 0.10 & 0.03 & 0.16 & $<0.01$ \\
\hline & CRP (3 months)* & 0.14 & 0.06 & 0.23 & $<0.01$ \\
\hline \multirow{7}{*}{$\begin{array}{l}\text { Sensitivity analysis } \\
\text { adjusting for } \\
\text { baseline CRP }\end{array}$} & Ventilator days* & 0.08 & -0.11 & 0.27 & 0.42 \\
\hline & Age & 0.00 & -0.01 & 0.01 & 1.00 \\
\hline & Gender & 0.08 & -0.19 & 0.36 & 0.56 \\
\hline & APACHE 2 & 0.01 & -0.02 & 0.02 & 0.63 \\
\hline & $\mathrm{FCl}$ & 0.11 & 0.04 & 0.17 & $<0.01$ \\
\hline & CRP (3 months)* & 0.14 & 0.05 & 0.23 & $<0.01$ \\
\hline & CRP* (ICU discharge) & 0.04 & -0.09 & 0.16 & 0.59 \\
\hline \multicolumn{6}{|c|}{$\begin{array}{l}\text { Outcome variable was } \ln (16-\mathrm{RMI}) \text {. } \\
\text { *Ventilator days and CRP were natural log transformed. Analyses conducted on the } \\
\text { cohort of } 123 \text { patients who had blood sampling at } 3 \text { months. A complete case } \\
\text { analysis approach was employed. } \\
\text { CRP, C-reactive protein; FCl, functional co-morbidity index; ICU, intensive care unit; } \\
\text { RMI, Rivermead Mobility Index. }\end{array}$} \\
\hline
\end{tabular}

and blood for inflammatory profiles was not collected during readmissions. It is possible that the condition requiring readmission resulted in worsening inflammation, which might explain some of our findings. Equally, a persisting inflammatory state may have limited recovery resulting in further hospitalisation. Further research is required to investigate this issue. Of the patients who had blood samples at 3 months, 11/123 (9\%) were hospital inpatients at the time. These patients had elevated CRP concentrations (median 15.8 (IQR 11.5-36.0) $\mathrm{mg} / \mathrm{L}$ versus 3.8 (IQR 1.0-9.4)).

Inflammation at hospital discharge has been associated with higher longer term mortality following acute illness in previous studies, ${ }^{41}$ but ours is the first to explore the association with physical recovery following critical illness. Persisting physical disability was related to inflammatory response 3 months after ICU discharge but not ICU discharge, suggesting that chronic persistent inflammation is more important than acute inflammation. This may explain why IL-6 and IL-1 $\beta$, which are early pro-inflammatory mediators, were not associated with late physical function, whereas others (CRP, IL-8, HNE and SLPI) were associated. Another potentially important consideration is that measurement of circulating soluble inflammatory biomarkers may not adequately characterise the host inflammatory response. For example, immune cell functions (eg, neutrophil apoptosis) and inflammatory processes localised to specific sites (eg, skeletal muscle or lung) may not be adequately described. Although our data should be interpreted with caution, they support the hypothesis that a persisting proinflammatory phenotype might mediate poorer physical recovery.

Inflammation is important in acute muscle loss in ICU patients ${ }^{8}$ and is associated with muscle function in chronic inflammatory disease. ${ }^{9-12}$ Inflammatory cytokines have an established role in regulating muscle mass; tumour necrosis factor $\alpha$, IL-6 and endotoxin cause muscle wasting ${ }^{42}$ due to increased protein catabolism, ${ }^{43}$ inhibition of protein synthesis, ${ }^{44}$ inhibition of muscle cell differentiation ${ }^{45}$ and reduced amino acid uptake. $^{46}$ It is possible that these processes 'block' clinical responses to physical rehabilitation in the early post-ICU period, which might explain the negative results of intervention trials in the early post-ICU period, including the RECOVER trial. Future 
Table 7 Biomarker concentration according to HCMV exposure group

\begin{tabular}{|c|c|c|c|c|}
\hline & $\begin{array}{l}\text { Previous HCMV exposure } \\
\text { Median (IQR) }\end{array}$ & $\begin{array}{l}\text { No previous HCMV exposure } \\
\text { Median (IQR) }\end{array}$ & $\begin{array}{l}\text { Hodges-Lehmann median } \\
\text { difference }(95 \% \mathrm{Cl})\end{array}$ & $p$ Value \\
\hline \multicolumn{5}{|l|}{ CRP (mg/L) } \\
\hline Baseline & $25.4(10.9-62.3)$ & $27.9(11.7-56.8)$ & $-0.5(-8.2$ to 8.2$)$ & 0.83 \\
\hline 3 months & $5.4(1.7-12.9)$ & $2.8(0.81-8.3)$ & $1.5(-0.1$ to 3.9$)$ & 0.06 \\
\hline \multicolumn{5}{|l|}{ HNE (ng/mL) } \\
\hline Baseline & $175.2(133.4-233.7)$ & $135.0(108.7-211.6)$ & 35.8 (14.0 to 58.7 ) & $<0.01$ \\
\hline 3 months & $118.1(95.6-158.2)$ & $91.3(76.2-120.4)$ & 35.8 (13.4 to 41.3$)$ & $<0.01$ \\
\hline \multicolumn{5}{|l|}{ IL-1 $\beta$ (pg/mL) } \\
\hline Baseline & $0.0(0.0-16.5)$ & $0.0(0.0-7.1)$ & $0.0(0.0$ to 0.0$)$ & 0.14 \\
\hline 3 months & $0.0(0.0-16.0)$ & $0.0(0.0-2.5)$ & $0.0(0.0$ to 0.0$)$ & 0.62 \\
\hline \multicolumn{5}{|l|}{ IL-6 (pg/mL) } \\
\hline Baseline & $31.1(8.5-97.6)$ & $16.4(6.5-63.5)$ & 8.1 (0.0 to 20.8$)$ & 0.24 \\
\hline 3 months & $7.1(0.1-51.2)$ & $1.5(0.0-14.3)$ & 8.1 (0.0 to 20.8 ) & 0.32 \\
\hline \multicolumn{5}{|l|}{ IL-8 (pg/mL) } \\
\hline Baseline & $35.8(14.7-74.0)$ & $24.4(11.2-40.2)$ & $7.5(-0.6$ to 17.2$)$ & 0.07 \\
\hline 3 months & $9.3(1.9-41.0)$ & $4.8(0.3-11.9)$ & 3.4 (0.0 to 9.5$)$ & 0.16 \\
\hline \multicolumn{5}{|c|}{ TGFß1 (ng/mL) } \\
\hline Baseline & $10.7(7.8-15.3)$ & $14.3(10.2-17.8)$ & $-2.4(-4.1$ to -2.4$)$ & 0.03 \\
\hline 3 months & $9.2(7.5-11.8)$ & $11.4(9.8-13.2)$ & $-1.7(-2.9$ to -0.4$)$ & 0.01 \\
\hline \multicolumn{5}{|l|}{ SLPI (ng/mL) } \\
\hline Baseline & $56.5(41.4-79.7)$ & $60.5(48.2-73.2)$ & $-2.9(-9.7$ to 4.3$)$ & 0.26 \\
\hline 3 months & $46.6(37.3-63.4)$ & $47.9(37.5-59.0)$ & $-0.4(-7.6$ to 7.0$)$ & 0.79 \\
\hline
\end{tabular}

rehabilitation research should consider including measures of inflammation during recovery in order to understand its importance as an effect modifier, and potentially to inform the optimum timing of interventions. In addition, metrics such as muscle volume and muscle biopsy may provide greater insight into the pathophysiological relationship between inflammation and neuromuscular recovery in future studies. ${ }^{4} 47$

Our finding of a proinflammatory phenotype in patients previously exposed to HCMV was unexpected. The original analysis was planned to explore the importance of active (lytic) infection but the small number of patients that this affected precluded this. Lytic infection is associated with activation of the innate immune system and previous studies have shown that this can last beyond the acute infection and into latency. ${ }^{21}$

Table 8 Comparison of physical outcomes in ICU survivors at 3 months in patients with/without previous HCMV exposure

\begin{tabular}{llll}
\hline & $\begin{array}{l}\text { Previous HCMV } \\
\text { exposure } \\
(\mathbf{n = 1 1 5 )}\end{array}$ & $\begin{array}{l}\text { No previous } \\
\text { HCMV exposure } \\
(\mathbf{n}=68)\end{array}$ & p Value \\
\hline $\begin{array}{l}\text { Rivermead Mobility Index } \\
\text { (median (Q1, Q3)) }\end{array}$ & $13(11,14)$ & $14(12,15)$ & 0.09 \\
$\begin{array}{l}\text { Hand grip strength (kg) } \\
\text { (mean (SD)) }\end{array}$ & $21(9)$ & $23(9)$ & 0.29 \\
$\begin{array}{l}\text { Timed up and go (s) (median } \\
\text { (Q1, Q3)) }\end{array}$ & $11(8,14)$ & $10(7,12)$ & 0.03 \\
$\begin{array}{l}\text { Physical component score of } \\
\text { SF12v2 (mean (SD)) }\end{array}$ & $35(11)$ & $35(12)$ & 0.85 \\
\hline
\end{tabular}

Rivermead Mobility Index data available for 106 exposed and 60 unexposed patients. Hand grip strength data available for 93 exposed and 52 unexposed patients. Timed up and go data available for 88 exposed and 51 unexposed patients. Physical component score of SF12v2 available for 95 exposed and 57 unexposed patients. HCMV, human cytomegalovirus; ICU, intensive care unit.
It has been reported that up to $40 \%$ of patients reactivate HCMV during critical illness ${ }^{14}$ so our previously exposed patients may have experienced reactivation at an early stage that was undetectable at our chosen measurement point. It is impossible to discriminate between the relative importance of latent and lytic infection in this study, but our data raise the possibility that HCMV is potentially important in post-ICU inflammation and recovery. Further research in this area is justified, because the clinical effects of HCMV activation are potentially modifiable by antiviral treatment. Two ongoing RCTs (the GRAIL study: NCT01335932 and the CCC study: NCT010503918) may provide more information, but neither will report functional outcome, or longer term inflammatory resolution.

Table 9 Baseline characteristics according to HCMV exposure

\begin{tabular}{|c|c|c|}
\hline & $\begin{array}{l}\text { Previous HCMV } \\
\text { exposure } \\
\text { ( } n=115)\end{array}$ & $\begin{array}{l}\text { No previous } \\
\text { HCMV exposure } \\
(n=68)\end{array}$ \\
\hline Age (mean (SD)) & $61(14)$ & $61(13)$ \\
\hline Male (n (\%)) & $69(63)$ & $43(60)$ \\
\hline $\begin{array}{l}\text { Functional co-morbidity index } \\
\text { (mean (SD)) }\end{array}$ & $3(2)$ & $3(2)$ \\
\hline APACHE 2 (mean (SD)) & $21(7)$ & $21(8)$ \\
\hline $\begin{array}{l}\text { Days of mechanical ventilation } \\
\text { (median (Q1, Q3)) }\end{array}$ & $8(5,13)$ & $7(4,16)$ \\
\hline ICU length of stay (median (Q1, Q3)) & $11(6,18)$ & $11(6,20)$ \\
\hline Vasopressors (n (\%)) & $83(73)$ & $49(72)$ \\
\hline Renal replacement therapy (n (\%)) & $34(30)$ & $15(22)$ \\
\hline
\end{tabular}

HCMV, human cytomegalovirus; ICU, intensive care unit. 
We observed a mean $1 \mathrm{~s}$ increase in the time taken to perform TUG in individuals who were HCMV seropositive. While this difference is small, it is a potentially important finding in terms of hypothesis generation, particularly as the RECOVER study found no difference between intervention groups in relation to this measure. Despite this the study was never powered to detect such a difference, and the finding should be interpreted with caution.

In conclusion, we have shown that a systemic proinflammatory state persists for at least 3 months in many patients recovering from critical illness, and is characterised by persisting proinflammatory signals and reduced proresolution signals. Persisting systemic inflammation is associated with poorer physical recovery. Although patients do not demonstrate evidence of ongoing lytic HCMV infection, those with evidence of previous HCMV infection appear to demonstrate a more persisting proinflammatory state that lasts beyond the ICU discharge and is present in some patients 3 months later. Further research is warranted to explore the importance of persisting inflammation as a mediator of recovery following critical illness.

\section{Twitter Follow David Griffith at @Griffith_DM}

Collaborators RECOVER investigators: T S Walsh, L G Salisbury, J L Merriweather, J A Boyd, D M Griffith, G Huby, S Kean, S J Mackenzie, A Krishan, S C Lewis, G D Murray, J F Forbes, J Smith, J E Rattray, A M Hull, P Ramsay, C Wallis, J Stewart, A Bateman, E Wilson, M Gillies, D Hope, H Dawson, C McCulloch, J Antonelli, L Boardman, L Dow, W Williams, A McCann, S Alexander, J Norrie, M Dennis, C Waldmann and S Brett.

Contributors TSW and DMG conceived the study. TSW, DMG, AGR and SL acquired funding. TSW, DMG, AGR, SL, LS, JM and KT designed the study. DMG and JR performed the biomarker assays. KT coordinated the HCMV analysis. All authors contributed to the interpretation of the summary data and reviewed the final manuscript. All authors approved the final version.

Funding This study was funded by the Chief Scientists Office, Scotland (CZH/4/531, $\mathrm{ETM} / 221$ ).

Competing interests None declared.

Ethics approval Scotland A REC (10/MRE0018).

Provenance and peer review Not commissioned; externally peer reviewed.

\section{REFERENCES}

1 Herridge MS, Tansey CM, Matté A, et al. Functional disability 5 years after acute respiratory distress syndrome. N Engl J Med 2011;364:1293-304.

2 Stevens RD, Marshall SA, Cornblath DR, et al. A framework for diagnosing and classifying intensive care unit-acquired weakness. Crit Care Med 2009;37: S299-308.

3 Hund E. Myopathy in critically ill patients. Crit Care Med 1999;27:2544-7.

4 Puthucheary ZA, Rawal J, McPhail M, et al. Acute skeletal muscle wasting in critical illness. Jama 2013;310:1591-600.

5 Fan E, Cheek F, Chlan L, et al. An official American Thoracic Society Clinical Practice guideline: the diagnosis of intensive care unit-acquired weakness in adults. Am J Respir Crit Care Med 2014;190:1437-46.

6 Connolly B, Salisbury L, O'Neill B, et al. Exercise rehabilitation following intensive care unit discharge for recovery from critical illness. In: The Cochrane Collaboration, ed. Cochrane database of systematic reviews. Chichester, UK: John Wiley \& Sons, Ltd, 2015. http://doi.wiley.com/10.1002/14651858.CD008632.pub2 (accessed 12 Nov 2015).

7 Walsh TS, Salisbury LG, Merriweather JL, et al. Increased Hospital-Based Physical Rehabilitation and Information Provision After Intensive Care Unit Discharge: The RECOVER Randomized Clinical Trial. JAMA Intern Med 2015;175: 901-10.

8 Kress JP, Hall JB. ICU-acquired weakness and recovery from critical illness. N Engl J Med 2014;370:1626-35.

9 Eid $A A$, Ionescu AA, Nixon LS, et al. Inflammatory response and body composition in chronic obstructive pulmonary disease. Am J Respir Crit Care Med 2001;164:1414-18.

10 Raj DSC, Shah $\mathrm{H}$, Shah VO, et al. Markers of inflammation, proteolysis, and apoptosis in ESRD. Am J Kidney Dis 2003;42:1212-20.
11 Roubenoff $R$, Parise $H$, Payette $H A$, et al. Cytokines, insulin-like growth factor 1 , sarcopenia, and mortality in very old community-dwelling men and women: the Framingham Heart Study. Am J Med 2003;115:429-35.

12 Toth MJ, Ades PA, Tischler MD, et al. Immune activation is associated with reduced skeletal muscle mass and physical function in chronic heart failure. Int J Cardiol 2006;109:179-87.

13 Griffith DM, Vale ME, Campbell C, et al. Persistent inflammation and recovery after intensive care: a systematic review. J Crit Care Published Online First: 13 Jan 2016. doi:10.1016/j.jcrc.2016.01.011

14 Heininger $\mathrm{A}$, Haeberle $\mathrm{H}$, Fischer $\mathrm{I}$, et al. Cytomegalovirus reactivation and associated outcome of critically ill patients with severe sepsis. Crit Care 2011;15:R77.

15 Heininger $A$, Jahn $G$, Engel $C$, et al. Human cytomegalovirus infections in nonimmunosuppressed critically ill patients. Crit Care Med 2001; 29:541-7.

16 Limaye AP, Kirby KA, Rubenfeld GD, et al. Cytomegalovirus reactivation in critically ill immunocompetent patients. JAMA 2008;300:413-22.

17 Cook CH, Martin LC, Yenchar JK, et al. Occult herpes family viral infections are endemic in critically ill surgical patients. Crit Care Med 2003;31. 1923-9.

18 Jaber $\mathrm{S}$, Chanques $\mathrm{G}$, Borry J, et al. Cytomegalovirus infection in critically ill patients: associated factors and consequences. Chest 2005;127:233-41.

19 Chiche L, Forel JM, Roch A, et al. Active cytomegalovirus infection is common in mechanically ventilated medical intensive care unit patients. Crit Care Med 2009;37:1850-7

20 Jackson SE, Mason GM, Wills MR. Human cytomegalovirus immunity and immune evasion. Virus Res 2011;157:151-60.

21 van de Berg PJ, Heutinck KM, Raabe R, et al. Human cytomegalovirus induces systemic immune activation characterized by a type 1 cytokine signature. $J$ Infect Dis 2010;202:690-9.

22 Walsh TS, Salisbury LG, Boyd J, et al. A randomised controlled trial evaluating a rehabilitation complex intervention for patients following intensive care discharge: the RECOVER study. BMJ Open 2012;2. pii: e001475.

23 Ramsay P, Salisbury LG, Merriweather JL, et al. A rehabilitation intervention to promote physical recovery following intensive care: a detailed description of construct development, rationale and content together with proposed taxonomy to capture processes in a randomised controlled trial. Trials 2014;15:38.

24 Collen FM, Wade DT, Robb GF, et al. The Rivermead Mobility Index: a further development of the Rivermead Motor Assessment. Int Disabil Stud 1991;13: 50-4.

25 Massy-Westropp NM, Gill TK, Taylor AW, et al. Hand Grip Strength: age and gender stratified normative data in a population-based study. BMC Res Notes 2011:4:127.

26 Podsiadlo D, Richardson S. The timed "Up \& Go": a test of basic functional mobility for frail elderly persons. J Am Geriatr Soc 1991;39:142-8.

27 Ware J Jr, Kosinski M, Keller SD. A 12-Item Short-Form Health Survey: construction of scales and preliminary tests of reliability and validity. Med Care 1996:34:220-33.

28 Shine $B$, de Beer FC, Pepys MB. Solid phase radioimmunoassays for human C-reactive protein. Clin Chim Acta 1981;117:13-23.

29 Groll DL, Heyland DK, Caeser M, et al. Assessment of long-term physical function in acute respiratory distress syndrome (ARDS) patients: comparison of the Charlson Comorbidity Index and the Functional Comorbidity Index. Am J Phys Med Rehabil 2006;85:574-81.

30 Sterne JAC, White IR, Carlin JB, et al. Multiple imputation for missing data in epidemiological and clinical research: potential and pitfalls. BMJ 2009;338: b2393.

31 Mislevy RJ, Little RJA, Rubin DB. Review of statistical analysis with missing data. J Educ Stat 1991;16:150-5.

32 Wang Z, Chen F, Zhai R, et al. Plasma neutrophil elastase and elafin imbalance is associated with acute respiratory distress syndrome (ARDS) development. PLOS ONE 2009;4:e4380.

33 Antonelli $A$, Ferri $C$, Ferrari SM, et al. Serum levels of proinflammatory cytokines interleukin-1 $\beta$, interleukin-6, and tumor necrosis factor $\alpha$ in mixed cryoglobulinemia. Arthritis Rheum 2009;60:3841-7.

34 Kobawala TP, Patel GH, Gajjar DR, et al. Clinical utility of serum interleukin-8 and interferon-alpha in thyroid Diseases. J Thyroid Res J Thyroid Res 2011; 2011: e270149.

35 Lin $Y$, Nakachi $K$, Ito $Y$, et al. Variations in serum transforming growth factor- $\beta 1$ levels with gender, age and lifestyle factors of healthy Japanese adults. Dis Markers 2009;27:23-8.

36 Grobmyer SR, Barie PS, Nathan CF, et al. Secretory leukocyte protease inhibitor, an inhibitor of neutrophil activation, is elevated in serum in human sepsis and experimental endotoxemia. Crit Care Med 2000;28:1276-82.

37 Staras SA, Dollard SC, Radford KW, et al. Seroprevalence of cytomegalovirus infection in the United States, 1988-1994. Clin Infect Dis 2006;43: $1143-51$. 
38 Fan E, Dowdy DW, Colantuoni E, et al. Physical complications in acute lung injury survivors: a two-year longitudinal prospective study. Crit Care Med 2014;42:849-59.

39 Groll DL, To T, Bombardier C, et al. The development of a comorbidity index with physical function as the outcome. J Clin Epidemiol 2005;58:595-602.

40 Bateman AP, McArdle F, Walsh TS. Time course of anemia during six months follow up following intensive care discharge and factors associated with impaired recovery of erythropoiesis. Crit Care Med 2009:37:1906-12.

41 Yende S, D'Angelo G, Kellum JA, et al. Inflammatory Markers at Hospital Discharge Predict Subsequent Mortality after Pneumonia and Sepsis. Am J Respir Crit Care Med 2008;177:1242-7.

42 Fong $\mathrm{Y}$, Moldawer LL, Marano M, et al. Cachectin/TNF or IL-1 alpha induces cachexia with redistribution of body proteins. Am J Physiol 1989;256(Pt 2): R659-65.
43 Baracos V, Rodemann HP, Dinarello CA, et al. Stimulation of muscle protein degradation and prostaglandin E2 release by leukocytic pyrogen (interleukin-1). A mechanism for the increased degradation of muscle proteins during fever. N Engl J Med 1983;308:553-8.

44 Charters $Y$, Grimble RF. Effect of recombinant human tumour necrosis factor alpha on protein synthesis in liver, skeletal muscle and skin of rats. Biochem J 1989;258:493-7.

45 Miller SC, Ito $\mathrm{H}$, Blau HM, et al. Tumor necrosis factor inhibits human myogenesis in vitro. Mol Cell Biol 1988;8:2295-301.

46 Zamir $\mathrm{O}$, Hasselgren PO, James $\mathrm{H}$, et al. Effect of tumor necrosis factor or interleukin-1 on muscle amino acid uptake and the role of glucocorticoids. Surg Gynecol Obstet 1993;177:27-32.

47 Connolly B, MacBean V, Crowley C, et al. Ultrasound for the assessment of peripheral skeletal muscle architecture in critical illness: a systematic review. Crit Care Med 2015;43:897-905. 